\title{
Efektivitas Program Aquatic Exercise Terhadap Penurunan Nyeri Pasien Chronic Low Back Pain
}

\author{
Cafin Surya Putra Pratama ${ }^{1}$, Arif Pristianto ${ }^{2}$, Isnaini Herawati ${ }^{3}$, Widya Ervianta ${ }^{4}$, Muh \\ Ridhuwan $^{5}$ \\ ${ }^{1,2,3}$ Program Studi Fisioterapi, Fakultas Ilmu Kesehatan, Universitas Muhammadiyah Surakarta \\ ${ }^{4,5}$ Rumah Sakit Tentara dr. Soedjono Magelang \\ email : cafinsurya7@gmail.com
}

Tanggal Submisi: 10 Maret 2020; Tanggal Penerimaan: 6 April 2020

\begin{abstract}
ABSTRAK
Chronic low back pain (CLBP) atau nyeri punggung bawah kronis didefinisikan kurangnya koordinasi dan lemahnya daya tahan otot disekitar tulang belakang dan core muscle yang dapat menyebabkan spasme otot berlangsung selama 12 minggu. Nyeri low back pain terjadi akibat adanya penurunan kekuatan dan daya tahan otot abdominals dan gluteus maximus serta ketegangan otot pada iliopsoas dan erector spine. Memanfaatkan fisika air seperti daya apung untuk mengurangi tekanan pada sendi, viskositas untuk latihan tahanan, tekanan hidrostatik mengurangi tekanan darah ke jantung dan penggunaan suhu air kisaran $33^{\circ}-37^{\circ} \mathrm{C}$ dapat menurunkan tonus otot dan mengurangi muscle guarding. Untuk mengetahui efektivitas program aquatic exercise terhadap penurunan nyeri pada pasien chronic low back pain di RST dr. Soedjono Magelang. Jenis penelitian yang digunakan adalah Quasi Experimental Design dengan pendekatan One Group Pre-Test dan Post-Test. Teknik pengambilan sampel dalam penelitian ini menggunakan purposive sampling. Jumlah sampel sebanyak 11 orang. Hasil Uji Paired Sample t-Test rata-rata pengukuran nyeri sebelum dan sesudah perlakuan sebesar 6,82 dan 4,45. Hasil uji statistik diperoleh p adalah 0,001. Kesimpulan dalam penelitian ini Aquatic exercise efektif terhadap penurunan nyeri pasien chronic low back pain pada RST dr. Soedjono Magelang.
\end{abstract}

Kata kunci: chronic low back pain, aquatic exercise, penurunan nyeri, fisika air

\section{ABSTRACT}

Chronic low back pain (CLBP) is defined as a lack of coordination and weak endurance of the muscles around the spine and core muscle which can cause muscle spasms to last for 12 weeks Low back pain occurs due to decreased strength and endurance of the abdominals and gluteus maximus muscles and muscle tension in the iliopsoas and erector spine. Utilizing water physics such as buoyancy to reduce pressure on the joints, viscosity for resistance training, hydrostatic pressure reduces blood pressure to the heart and the use of water temperatures in the range of $33^{\circ}-37^{\circ} \mathrm{C}$ can reduce muscle tone and reduce muscle guarding. To determine the effectiveness of the aquatic exercise program to decrease pain in chronic low back pain patients in RST dr. Soedjono Magelang. The type of research used is Quasi Experimental Design with One Group Pre-Test and Post-Test approaches. The sampling technique in this study used purposive sampling. The number of samples is 11 people. Paired Sample t-Test Results, the average measurement of pain before and after treatment was 6,82 and 4,45. The statistical test results obtained $\mathrm{p}$ is 0.001 . Aquatic exercise is effective against decreased the pain of chronic low back pain patients on RST dr. Soedjono Magelang.

Keywords: chronic low back pain, aquatic exercise, decrease pain, water physics.

\section{PENDAHULUAN}

Low back pain adalah gejala rasa sakit yang dapat dilokalisasi antara tulang rusuk kedua belas dan lipatan gluteal inferior (punggung bawah), dengan atau tanpa nyeri tungkai bawah(sciatica) dan bukan suatu penyakit (Chou, 2010). Low back pain diklasifikasikan menjadi 3 berdasarkan jangka waktunya, low back pain akut kurang dari 4 minggu, low back pain subakut 4 minggu, low back pain kronis berlangsung lebih dari 12 minggu (van Middelkoop et al., 2010).

Menurut penelitian (Meucci et al., 2015), prevalensi low back pain pada usia 50 tahun lebih tinggi tiga sampai empat kali lipat dibandingkan dengan usia 18 hingga 30 tahun dan low back pain kronis pada individu yang berusia 24 - 39 tahun adalah $4,2 \%$ dan pada usia 20-59 tahun adalah 19,6\% . 
Menurut (Verhagen et al., 2012) aquatic exercise menghasilkan efek fisiologis dari prinsip perendaman dan hidrodinamik dari latihan di lingkungan akuatik, seperti daya apung memilki prinsip untuk mengurangi beban gravitasi bumi dan menguragi compressive weight-bearing dan efek tekanan hidrostastik dapat mengurangi pembengkakkan dan persepsi nyeri pada muskuloskeletal. Penelitian sebelumnya yang dilakukan (Bello et al., 2010)telah mendapatkan hasil dengan program aquatic exercise selama 6 minggu, mereka menunjukkan bahwa aquatic exercise menghasilkan peningkatan fleksibilitas tulang belakang.

Berdasarkan latar belakang di atas, maka peneliti tertarik untuk melakukan penelitian apakah aquatic exercise efektif terhadap penurunan nyeri pasien chronic low back pain. Oleh karena itu, peneliti mengambil penelitian yang berjudul "Efektivitas Program Aquatic Exercise Terhadap Penurunan Nyeri Pasien Chronic Low Back Pain Di RST dr. Soedjono Magelang".

\section{METODE PENELITIAN}

Penelitian ini dilaksanakan di RST dr. Soedjono Magelang. Adapun waktu penelitian ini dilaksanakan tanggal 17 Desember 2019 sampai 16 Januari 2020. Jenis penelitian yang digunakan dalam penelitian adalah ini adalah Quasi Experimental Design. Desain penelitian yang digunakan dalam penelitian ini adalah One Group Pre-Test dan Post-Test. Jumlah sampel yang akan diteliti berjumlah 11 orang. Variabel bebas dalam penelitian ini adalah aquatic exercise. Variabel terikat dalam penelitian ini adalah penurunan nyeri pasien chronic low back pain.

\section{HASIL}

Penelitian dilaksanaakan di RST dr. Soedjono Magelang dengan subyek penelitiannya adalah pasien fisioterapi yang mengalami keluhan chronic low back pain khususnya usia 30-65 tahun. Jumlah sampel sebanyak 11 orang, dimana 8 berjenis kelamin perempuan dan 3 berjenis kelamin laki-laki.
Pengukuran dilakukan sebelum dan sesudah diberikan terapi (pretest dan posttest). Waktu penelitian yaitu dimulai tanggal 17 Desember 2019 sampai 16 Januari 2020. Penelitian dilakukan pukul 09.00 sampai 11.00 WIB.

\section{Tabel 1. Data Karakteristik}

\begin{tabular}{|c|c|c|c|}
\hline NO & Karakteristik & Frekuensi & $\%$ \\
\hline \multirow[t]{4}{*}{1} & Jenis Kelamin & & \\
\hline & a. Laki-Laki & 3 & 27.3 \\
\hline & b. Perempuan & 8 & 72.7 \\
\hline & Total & 11 & 100 \\
\hline \multirow[t]{6}{*}{2} & Usia & & \\
\hline & a. $36-42$ & 1 & 9,1 \\
\hline & b. $43-50$ & 5 & 45,5 \\
\hline & c. $51-58$ & 1 & 9,1 \\
\hline & d. $59-65$ & 4 & 36,4 \\
\hline & Total & 11 & 100 \\
\hline \multirow[t]{11}{*}{3} & Index Massa Tubuh & & \\
\hline & a. BB Normal & 2 & 18.2 \\
\hline & b. Pre Obesitas & 7 & 63.6 \\
\hline & c. Obesitas & 2 & 18.2 \\
\hline & Pekerjaan & & \\
\hline & a. IRT & 7 & 63.6 \\
\hline & Rumah Tangga) & & \\
\hline & b. PNS & 1 & 9.1 \\
\hline & c. TNI & 1 & 9.1 \\
\hline & d. Pensiunan & 2 & 18.2 \\
\hline & Total & 11 & 100 \\
\hline
\end{tabular}

Tabel 2. Uji Normalitas

\begin{tabular}{llll}
\hline \multirow{2}{*}{ Perlakuan } & \multicolumn{3}{l}{ Shapiro-Wilk } \\
\cline { 2 - 4 } & Statistic & df & Sig. \\
\hline Pretest & 0,896 & 11 & 0,165 \\
\hline Posttest & 0,878 & 11 & 0,098 \\
\hline
\end{tabular}

Data hasil tabel 3.2 didapatkan bahwa uji normalitas dengan Shapiro-Wilk Test pada efektivitas program aquatic exercise terhadap penurunan nyeri pasien chronic low back pain pada pretest dan posttest memiliki nilai $\mathrm{p}>$ 0,05 sehingga dapat disimpulkan bahwa nilai uji normalitas bersifat normal. 
Tabel 3. Uji Pengaruh

\begin{tabular}{lllll}
\hline & Mean & N & $\begin{array}{l}\text { Std. } \\
\text { Deviation }\end{array}$ & Sig. \\
Pretest & 6,82 & 11 & 0,982 & 0,001 \\
Posttest & 4,45 & 11 & 1,293 & \\
\hline
\end{tabular}

Pada penggunaan Uji Paired Sample tTest mengidentifikasikan pengaruh sebelum dan setelah pemberian latihan pada responden yang mengalami chronic low back pain. Berdasarkan tabel di atas, rata-rata pengukuran nyeri sebelum dan sesudah perlakuan sebesar 6,82 dan 4,45. Hasil uji statistik diperoleh $\mathrm{p}$ adalah 0,001 , maka dapat disimpulkan bahwa ada pengaruh pada pemberian aquatic exercise terhadap penurunan nyeri pasien chronic low back pain karena $\mathrm{p}<0,05$.

\section{PEMBAHASAN}

Berdasarkan hasil data penelitian, jenis kelamin yang paling banyak mengalami chronic low back pain adalah perempuan sebanyak 8 orang $(72,72 \%)$. Hormon wanita sangat berpengaruh terhadap etiologi dan pastofisiologi penyakit degeratif muskuloskeletal terutama terjadi pada wanita menepouse yang mengalami penurunan kemampuan otot (Wang, 2017).

Data hasil penelitian diketahui bahwa usia kelompok perlakuan yang jumlahnya terbanyak adalah 43-50 tahun usia tahun. Menurut Manchikanti et al. (2014) rentang usia 35-55 tahun merupakan frekuensi tertinggi terjadinya low back pain seiring dengan bertambahnya usia. Faktor usia menyebabkan penurunan fungsi seperti hilangnya kekuatan otot dan gangguan mobilitas yang mengakibatkan meningkatkan risiko jatuh dan menurunkan kemandirian (Bigos et al., 2009).

Karakteristik pekerjaan responden yang memiliki chronic low back pain sebanyak 7 orang $(63,63 \%)$ bekerja sebagai ibu rumah tangga. Menurut Kwon et al, (2011) faktor terjadinya low back pain akibat pekerjaan meliputi pekerjaan fisik yang berat, postur tubuh yang selalu sama dan getaran seluruh tubuh

Pada penelitian ini data terbanyak indeks massa tubuh masuk kedalam kategori kecendrungan obesitas sesuai dengan tabel 4.2 $(63,6 \%)$. Orang dengan kondisi tubuh yang cenderung menuju obesitas dapat mengalami chronic low back pain dikarenakan berkurangnya lingkup gerak sendi tulang belakang karena adanya ketegangan otot erector spine dan terjadi kelemahan pada otot abdominal (Vismara et al., 2010).

Berdasarkan analisa data pengukuran numerical rating scale untuk mengetahui pengaruh program aquatic exercise terhadap penurunan nyeri pasien chronic low back pain sesuai dengan tabel 4.6 diperoleh hasil nilai probabilitas (nilai p) pada kelompok perlakuan adalah 0,001 hal ini menunjukkan nilai probabilitas kurang dari $0,05(\mathrm{p}<0,05)$ atau signifikan berpengaruh. Prabhu \& Dadmi (2019) menjelaskan dengan memanfaatkan sifat unik air seperti daya apung untuk menurunkan tekanan pada sendi, tulang, otot dan mengurangi nyeri saat sendi bergerak membentuk postur tubuh yang benar.

Viskositas juga dapat dimanfaatkan sebagai latihan untuk meningkatkan kekuatan otot dengan gerakan yang berkelanjutan dengan meningkatkan kecepatan dan luas area permukaan yang digerakkan (Taglietti et al., 2018). Tekanan hidrotastik dapat mengurangi tekanan darah ke jantung saat latihan (Shi et al., 2018). Penggunaan suhu air dengan kisaran $33^{\circ}-37^{\circ} \mathrm{C}$ dapat menurunkan tonus otot dan mengurangi muscle guarding sehingga dapat menurunkan nyeri (Sawant \& Shinde, 2019). Dengan prinsip aquatic tersebut dapat menurunkan nyeri dengan mekanisme adaptasi dan rileksasi. Pada program aquatic exercise terdapat dua jenis gerakan yaitu, akitf berupa strengthening dan pasif berupa stretching. Stretching diberikan agar otot yang mengalami pemendekan dapat memanjang untuk meningkatkan fleksibilitasnya (Sevimli et al., 2015), contoh gerakan yang diberikan berupa gerakan stretching thoracal and lumbar side bending. Strengthening diberikan untuk meningkatkan kekuatan otot-otot pada 
abdomen, lumbal dan pelvis (Pristianto et al., 2018), contoh gerakan yang diberikan adalah unilateral hip and knee flexion/extension.

Hasil penelitian ini tidak sepenuhnya mutlak berpengaruh dikarenakan masih adanya pasien yang menggunakan medikamentosa untuk mengurangi nyeri ketika sedang mengikuti program aquatic exercise. Dibuktikan dengan penelitian Romanò et al. (2012) bahwa dengan mengkombinasikan obat antinociceptive yaitu Selekoksib dan antineuropathic yaitu Pregabalin dapat menurunkan nyeri chronic low back pain.

\section{KESIMPULAN DAN SARAN}

Berdasarkan penelitian yang telah dilakukan, peneliti menyimpulkan bahwa aquatic exercise efektif terhadap penurunan nyeri pasien chronic low back pain. Selain itu penelitian ini juga menunjukan bahwa program aquatic exercise sehingga dapat diterapkan untuk mencegah dan mengurangi risiko terjadinya chronic low back pain.

Penelitian ini dapat memberikan pengetahuan terkait program aquatic exercise sehingga dapat diterapkan untuk mencegah dan mengurangi risiko terjadinya chronic low back pain. Adapun saran pada penelitian selanjutnya Disarankan untuk memonitoring konsumsi obat terhadap pasien agar mengurangi bias hasil data penelitian dan Disarankan untuk mengkontrol aktivitas responden agar mendapatkan hasil yang lebih maksimal.

\section{Daftar Pustaka}

Bello, A. I., Kalu, N. H., Adegoke, B. O. A., \& Agyepong-Badu, S. (2010). Hydrotherapy versus land-based exercises in the management of chronic low back pain: A comparative study. Journal of Musculoskeletal Research, 13(4), 159-165. https://doi.org/10.1142/S0218957710 002594

Bigos, S. J., Holland, J., Holland, C., Webster, J. S., Battie, M., \&
Malmgren,

J. A. (2009). High-quality controlled trials on preventing episodes of back problems: systematic literature review in working-age adults. Spine Journal, $\quad 9(2), \quad$ 147-168. https://doi.org/10.1016/j.spinee.2008. 11. 001

Chou, R. (2010). Low back pain (chronic). Clinical Evidance, 10(1116), 1-41.

Kwon, B. K., Roffey, D. M., Bishop, P. B.,Dagenais, S., \& Wai, E. K. (2011). Systematic review: Occupational physical activity and low back pain. Occupational Medicine, 61(8), 541548.

https://doi.org/10.1093/occmed/kqr09 2

Manchikanti, L., Singh, V., Falco, F. J. E., Benyamin, R. M., \& Hirsch, J. A. (2014). Epidemiology of low back pain in Adults. Neuromodulation, 17(S2), 3- 10. https://doi.org/10.1111/ner.12018

Meucci, R. D., Fassa, A. G., \& Xavier Faria, N. M. (2015). Prevalence of chronic low back pain: Systematic review. Revista de Saude Publica, 49, 1-10. https://doi.org/10.1590/S00348910.2015049005874

Prabhu, C., \& Dadmi, P. (2019). Effect of aquatic therapy $\mathrm{v} / \mathrm{s}$ relaxation therapy in chronic low back pain. International Journal of Orthopaedics Sciences, 5(1.3), 279284.

https://doi.org/10.22271/ortho.2019.v 5.i 1 e.49

Pristianto, Arif., Rahman, Farid, Wijianto. (2018). Terapi Latihan Dasar. Surakarta: Muhammadiyah University Press.

Romanò, C. L., Romanò, D., \& Lacerenza, M. (2012). Antineuropathic and antinociceptive drugs combination in patients with chronic low back pain: A systematic review. Pain Research and Treatment, 2012.

https://doi.org/10.1155/2012/154781

Sawant, R. S., \& Shinde, S. B. 
(2019). Effect

of hydrotherapy based exercises for chronic nonspecific low back pain. Indian Journal of Physiotherapy and Occupational Therapy - An International Journal, 13(1), 133.

https://doi.org/10.5958/09735674.2019.00027.3

Sevimli, D., Kozanoglu, E., Guzel, R., \& Yao, X., Feng, S. (2018). Aquatic Exercises in the Treatment of Low Back Pain: A Systematic Review of the Literature and Meta-Analysis of Eight Studies. American Journal of Physical Medicine and Rehabilitation, 97(2), 116-122.

https://doi.org/10.1097/PHM.000000000 0000801

Taglietti, M., Facci, L. M., Trelha, C. S., de Melo, F. C., da Silva, D. W., Sawczuk, G., ... Cardoso, J. R. (2018). Effectiveness of aquatic exercises compared to patienteducation on health status in individuals with knee osteoarthritis: a randomized controlled trial. Clinical Rehabilitation, 32(6), 766-776.

https://doi.org/10.1177/0269215517754 240

van Middelkoop, M., Rubinstein, S. M., Verhagen, A. P., Ostelo, R. W., Koes, B.

W., \& van Tulder, M. W. (2010). Exercise therapy for chronic nonspecific lowback pain. Best Practice and Research: Clinical Rheumatology,
Doganay, A. (2015). The effects of aquatic, isometric strength-stretching and aerobic exercise on physical and psychological parameters of female patients with fibromyalgia syndrome. Journal of Physical Therapy Science, 27(6), 1781-1786.

https://doi.org/10.1589/jpts.27.1781 Shi, Z., Zhou, H., Lu, L., Pan, B., Wei, Z., 24(2), 193204.

https://doi.org/10.1016/j.berh.2010.01.0 02 Verhagen, A. P., Cardoso, J. R., \& BiermaZeinstra, S. M. A. (2012). Aquatic exercise \& balneotherapy in musculoskeletal conditions. Best Practice and Research: Clinical Rheumatology, 26(3), 335343. https://doi.org/10.1016/j.berh.2012.05 .008

Vismara, L., Francesco, M., Zaina, F., Galli, M., Negrini, S., \& Capodaglio, P. (2010). Effect of obesity and low back pain on spinalmobility. Journal of NeuroEngineering and Rehabilitation, 3(7), 1-8.

Wang, Y. X. J. (2017). Menopause as a potential cause for higher prevalence of low back pain in women than in age- matched men. Journal of Orthopaedic Translation, 8, 1-4. https://doi.org/10.1016/j.jot.2016.05 